\title{
SISTEM PERBANKAN KONVENSIONAL DALAM PERSPEKTIF FIKIH MUAMALAT
}

\author{
Ayu Sandra Intan Aprilia \\ Institut Agama Islam Negeri Kediri \\ luluksafitri91@gmail.com \\ Luluk Safitri \\ Institut Agama Islam Negeri Kediri \\ luluksafitri91@gmail.com
}

\begin{abstract}
Abstrak
Di dalam muamalah, terdapat dua pihak yang bertransaksi yang berposisi sama baik dalam hak maupun kewajiban. Namun, kesan yang ditimbulkan dari undang-undang perbankan lebih banyak mengatur dan memproteksi bank sebagai lembaga keuangan. Sementara posisi nasabah tidak mendapatkan porsi yang cukup dalam undang-undang sehingga terkesan nasabah dalam suatu perjanjian lebih cenderung sebagai objek bukannya subjek. Prinsip muamalah sesungguhnya terimplementasi dalam hukum perbankan Indonesia, sebagaimana ditemukan dalam beberapa pasal dalam undang-undang perbankan, tetapi tidak berarti diimplementasikan. Artinya, ketika undang-undang disusun kuat dugaan tidak membawa pesan khusus untuk memasukkan prinsip-prinsip muamalah yang terimplementasi dalam undang-undang perbankan karena prinsip-prinsip muamalah bersifat unversal yang dijunjung tinggi oleh nilai-nilai kemanusiaan.
\end{abstract}

Kata Kunci: Bank Konvensional, Bunga, Riba, Fikih.

\begin{abstract}
In muamalah, there are two transaction parties who have the same position both in rights and obligations. However, the impression generated from the banking law regulates and protects banks as financial institutions. Meanwhile, the position of the customer does not get an adequate portion in the law so that the impression that the customer in an agreement is more likely to be an object rather than a subject. The principle of muamalah is actually implemented in Indonesian banking law, as found in several articles in the banking law, but it does not mean it is implemented. This means that when the law is drafted it is strongly suspected that it does not carry a special message to include muamalah principles which are implemented in banking law because muamalah principles are universal which are upheld by human values.
\end{abstract}

Keywords: Conventional Bank, Interest, Riba, Fiqh. 


\section{Pendahuluan}

Muamalah merupakan bagian dari hukum Islam yang mengatur hubungan antara dua pihak atau lebih, baik antara seorang pribadi dengan pribadi lain, maupun antar badan hukum seperti perseroan, firma, yayasan, negara, dan sebagainya. Awalnya cakupan muamalah di dalam fikih meliputi permasalahan keluarga seperti perkawinan dan perceraian. Akan tetapi, setelah terjadi disentegrasi di dunia Islam, khususnya di zaman Utsmani (Turki Ottoman), terjadi perkembangan pembiakan fikih. Cakupan bidang muamalah dipersempit sehingga masalah yang berhubungan dengan hukum keluarga tidak masuk lagi dalam pengertian muamalah. Hukum keluarga dan segala yang terkait dengannya disebut al-abwal al-asyakhshiyah (masalah pribadi). Muamalah kemudian difahami sebagai hukum yang berkaitan dengan perbuatan manusia dengan sesamanya yang menyangkut harta dan hak serta penyelesaian kasus di antara mereka. ${ }^{1}$ Pengertian ini memberikan gambaran bahwa muamalah hanya mengatur permasalahan hak dan harta yang muncul dari transaksi antara seseorang dengan orang lain, atau antara seseorang dengan badan hukum, atau antara badan hukum dengan badan hukum yang lain.

Bank adalah badan hukum atau lembaga keungan yang usaha pokoknya memberikan kredit dan jasa-jasa dalam lalu lintas pembayaran dan peredaran uang, dengan tujuan memenuhi kebutuhan kredit dengan modal sendiri atau orang lain.

Di dalam perekonomian modern, bank dipandang sebagai, yaitu 'industri perbankan' yang menghasilkan bermacam-macam produk berupa 'jasa' yang disebut dengan 'produk perbankan'. Produk ini ditawrkan kepada konsumen dengan syaratsyarat tertentu yang harus dipenuhi oleh kedua belah pihak dalam bertransaksi. Konsumen dimaksud adakalanya orang perorang, dan bisa juga badan hukum.

Sebagai badan hukum, perbankan di Indonesia diatur oleh undang-undang, yaitu Undang-undang Perbankan. Secara umum adanya undang-undang adalah untuk meminimalisir atau menghindari sama sekali perselisihan antara pihak bank dengan nasabahnya. Perselisihan bisa dihindari apabila di dalam undang-undang termuat

\footnotetext{
${ }^{1}$ Dewan Redaksi, Ensiklopedia Islam, Jilid 5 (Jakarta: Ichtiar Baru van Hoeve, 2005), 49.
} 
prinsip-prinsip yang pada intinya tidak merugikan salah satu atau kedua belah pihak yang melakukan transaksi.

Di dalam perekonomian global, sulit menemukan standar etika bisnis. Kesulitan itu, kata Tantri Abeng, terletak pada tidak adanya kesamaan pandangan yang universal terhadap etika bisnis itu sendiri. Apa yang dianggap etis di Indonesia belum tentu dapat di terima dan diartikan sama pada lingkungan masyarakat lain, misalnya Amerika Serikat. ${ }^{2}$

Kalau saja para ekonom sedikit menoleh kepada etika bisnis yang ada dalam Islam dan tidak berpandangan subyektif, ada nilai-nilai universal yang dijunjung tinggi oleh manusia beradab. Di dalam bermuamalah secara Islami, ada prinsip-prinsip etika yang harus dijunjung tinggi oleh pihak-pihak yang melakukan transaksi. Prinsipprinsip tersebut, tidak hanya dijunjung tinggi oleh manusia yang mengandung nilainilai universal, tapi juga bersumber dari wahyu. Dunia perbankan sebagai lembaga bisnis di Indonesia diatur oleh undang-undang. Tulisan ini membahas tentang sejauh mana prinsip-prinsip muamalah itu terimplementasi di dalam hukum perbankan.

\section{Metode Penelitian}

Penelitian ini menggunakan metode jenis deskriptif, yaitu yang bertujuan untuk memberikan gambaran secara sistematis, factual, akurat mengenai fakta-fakta, fenomena dan sifat-sifat yang terjadi mengenai kehidupan sekelompok sosial dan individu, suatu objek, populasi tertentu dan individu, suatu objek, populasi tertentu dan suatu peristiwa yang terjadi. Data yang digunakan adalah data sekunder yaitu data yang diperoleh secara tidak langsung seperti melalui dokumen-dokumen resmi, bukubuku, jurnal, dan literarur-literatur lain yang relevan dengan pembahasan jurnal ini. Teknik pengumpulan data yang digunakan adalah studi kepustakaan. Kemudian data dianalisis dengan metode analisis deskriptif sesuai dengan fakta yang ada.

Secara bahasa, kata bank berasal dari bahasa Italia banca, yang berarti "meja” atau "tempat menukarkan uang". Sedang istilah, bank ialah "Lembaga keuangan yang

\footnotetext{
${ }^{2}$ Tantri Abeng, "Pengaruh Aliansi Birokrasi dengan Pengusaha terhadap Etika Bisnis," Demokrasi Politik, Budaya dan Ekonomi Pengalaman Indonesia masa Orde Baru, ed. Elza Peldi Taher (Jakarta: Yayasan Paramadina, 1994), 85.
} 
usaha pokoknya memberikan kredit dan jasa di lalu lintas pembayaran dan peredaran uang”. ${ }^{3}$ Menurut Undang-Undang Republik Indonesia Nomor 10 Tahun 1998 tentang Perbankan, pengertian bank ialah "Badan usaha yang menghimpun dana dari masyarakat dalam bentuk simpanan dan menyalurkannya kepada masyarakat dalam bentuk kredit dana tau bentuk-bentuk lainnya dalam rangka meningkatkan taraf hidup rakyat banyak". ${ }^{4}$

Berdasarkan definisi-definisi di atas, dapat disimpulkan bahwa bank ialah perusahaan yang bergerak dalam bidang keuangan dengan tiga fungsi utama, yakni:

a. Menghimpun dana dari masyarakat

b. Menyalurkan dana kepada masyarakat

c. Memberikan jasa-jasa lainnya.

Kegiatan industri perbankan di Indonesia saat ini, ada dua model mencari keuntungan. Untuk bank konvensional, keuntungan diperoleh dari bunga pinjaman, dan untuk bank syariah, keuntungan diperoleh dari bagi hasil.

Sebagian besar bank konvensional, usahanya bergantung pada bunga. Bank mengumpulkan modal dari dana masyarakat dalam bentuk tabungan, lalu uang yang terhimpun dari dana masyarakat dipinjamkan dalam bentuk modal kepada pihak lain. Bank memberikan bunga kepada para penabung dan menarik bunga dari peminjam. Bunga yang ditarik jauh lebih besar daripada yang diberikan. Selisih antara dua bunga: peminjam dan penabung merupakan laba yang diperoleh bank. ${ }^{5}$

\section{Pembahasan}

Berdasarkan teori yang dipaparkan di atas, ada tiga fungsi atau kegiatan utama perbankan yakni menghimpun dana, menyalurkan dana, dan memberikan jasa-jasa lainnya kepada masyarakat. ${ }^{6}$

Menghimpun dana di sini ialah mengumpulkan uang dengan cara "membeli" dari masyarakat luas dalam bentuk simpanan giro, tabungan, dan deposito. Dalam

\footnotetext{
${ }^{3}$ Ahmad Wardi Muslich, Fiqh Muamalat (Jakarta: Penerbit Amzah, 2017), 498.

${ }^{4}$ Ismail, Manajemen Perbankan: Dari Teori Menuju Aplikasi (Jakarta: Penerbit Kencana, 2011), 3.

${ }^{5}$ Erwandi Tarmizi, Harta Haram Muamalat Kontemporer (Bogor: PT. Berkat Mulia Insani, 2018), 404.

${ }^{6}$ Muslich, Fiqh Muamalat, 498.
} 
mengumpulkan dana ini bank menggunakan berbagai macam strategi agar masyarakat mau memberikan dan menyimpan dananya di bank.

Strategi bank dalam menghimpun dana ialah dengan memberikan intensif berupa balas jasa yang menarik dan menguntungkan. Balas jasa tersebut antara lain berupa bunga bagi bank konvensional, dan bagi hasil bagi bank syariah. Selain itu juga memberikan rangsangan lain berupa cindera mata, hadiah, pelayanan yang mudah melalui sms banking, dan sebagainya.

Menyalurkan dana sendiri berarti memberikan kembali dana yang diperoleh melalui simpanan giro, tabungan, dan deposito kepada masyarakat dalam bentuk pinjaman atau kredit bagi bank konvensional, dan pembiayaan atau al-qardh al hasan bagi bank syariah. Bagi bank-bank yang menganut prinsip konvensional, di dalam memberikan kredit, selain dikenai bunga, penerima kredit juga dibebani jasa pinjaman lain, seperti biaya provisi dan komisi. Dan bank memperoleh keuntungan dari selisih bunga simpanan yang diberikan kepada penyimpan degan bunga pinjaman atau kredit yang disalurkan.

Jasa-jasa lain yang diberikan bank ialah jasa yang mendukung kelancaran atau melengkapi kegiatan menghimpun dana dan menyalurkan dana seperti:
a. Jasa setoran, seperti setoran telepon, listrik, air, atau uang kuliah
b. Jasa pembayaran, seperti pembayaran gaji, pensiun, atau hadiah
c. Jasa pengiriman uang (transfer)
d. Jasa kliring
e. Jasa penagihan (inkaso)
f. Jasa penjualan mata uang asing (valas)
g. Jasa penyimpanan dokumen
h. Jasa cek wisata
i. Jasa kartu kredit
j. Jasa-jasa yang ada di pasar modal seperti penjamin emisi
k. Jasa letter of credit
1. Jasa bank garansi dan referensi bank
m. Jasa-jasa bank lainnya 
Bank-bank komersial telah melalui banyak perubahan dalam sejarahnya. Berpindah dari lama, yang mana Bank bertanggung jawab atas operasi deposito dan kredit, di Negara Eropa dan lainnya di perusahan besar yang membantu memotivasi perdagangan, dan kemudian memperkenalkan orang-orang untuk menyetorkan uang mereka kepada bank, dan mendapatkan sertifikat yang berfungsi mengonfirmasi deposit ini. Pada tahap ini, pedagang berusaha untuk menyimpan uang untuk mendapatkan komisi. Bank-bank telah mewarisi prinsip menerima setoran dari publik.

Sedangkan pemberi pinjaman uang, yakni mereka yang meminjamkan uang mereka sebagai imbalan untuk komisi besar di awal. Bank telah mewarisi prinsip pinjaman berbunga-bunga ini. Mereka yang terlibat dalam perdagangan perhiasan, logam, dan dengan demikian memperoleh pengalaman dengan peluru logam, dan harga, orang-orang akan memperhitungkan perputaran uang koin.

Kemudian mereka memperdagangkan mata uang, Mereka juga mengembangkan pekerjaan mereka, menerima setoran dari publik dan memberikan sertifikat untuk membuktikan deposit ini (saham). Bank-bank mewarisi praktik kerja pertukaran, dan menerima simpanan dari publik. Bank-bank telah dimasukkan dalam warisan ini, Pertama kalinya bank difungsikan sebagai pertukaran dan penyimpanan uang rakyat dalam bentuk deposito, seperti bank-bank pada abad ke-12 dan ke-14 di Italia, Eropa Utara. Mereka melanjutkan fungsi-fungsi ini sampai awal abad ke-17. Bank-bank sedang berkembang, dan bank-bank telah menunjuk pemerintah dengan sejumlah besar simpanan masyarakat yang menganggur, pemerintah meminjaminya dengan bunga, dan dalam kerahasiaan penuh, agar pelanggan tidak merasa terkhawatirkan.

Lambat laun, para deposian mengambil sertifikat deposito mereka, yang menarik bank-bank untuk menyerahkan dan meminjamkannya dengan bebas sehingga itu merupakan langkah besar dalam pengembangan kredit.

Transaksi perbankan bank didasarkan pada, pertama, pekerja bank ini meminjam dari publik melalui apa yang disebut penerimaan deposito, dalam transakasi ini, bank adalah peminjam. Bank komersial membagi bank islam dalam hal ini satu sisi, bahwa bank umum membayar bunga untuk pinjaman ini, tidak seperti bank Islam. Kedua, pinjaman bunga karena bank meminjamkan uang kepada publik dengan 
imbalan bunga, ini disebut "kredit" atau "pembiayaan", yang merupakan dasar dari kerja bank komersial, dan dapat meminjamkannya untuk disetorkan kembali kepada bank bank besar.

\section{Pandangan Fikih Muamalat tentang Sistem Perbankan}

\section{Hukum Bunga Bank}

Pada hakikatnya bunga adalah pinjaman yang dibayar berlebih, maka hukumnya haram dan termasuk riba. Menabung di bank sekalipun dinamakan simpanan, akan tetapi dalam kacamata fikih akadnya adalah pinjaman (qardh). Secara terminologi fikih, qardh berarti menyerahkan uang kepada seseorang untuk dipergunakannya dan dikembalikan dalam bentuk uang senilai pinjaman. Pengertian ini sama dengan tabungan, dimana uang tabungan yang disimpan di bank digunakan oleh bank, lalu dikembalikan ketika kapanpun dibutuhkan oleh penabung dalam bentuk penarikan uang tabungan.

Seperti dinukil dari Ibnu Utsaimin, "Para ahli fikih menjelaskan bahwa bila orang yang menitipkan (uang) memberikan izin kepada yang dititip untuk menggunakannya, maka akad wadi'ab berubah menjadi akad qardh.” Itulah sebabnya mengapa para ulama tidak mengatakan akad ini sebagi akad wadi'ah (simpanan).

Jika hakikatnya adalah akad qardh, maka pinjaman tidak boleh dikembalikan berlebih, bila dikembalikan berlebih dalam bentuk bunga maka bunga ini dinamakan riba. Ada kaidah fikih yang menyatakan,

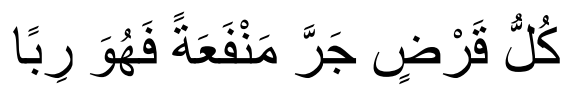

Setiap pinjaman yang memberikan keuntungan bagi pemberi pinjaman adalah riba.

Hukum yang menyatakan bahwa bunga bank sama dengan riba merupakan keputusan seluruh lembaga fatwa baik yang bertaraf internasional maupun nasional, sehingga bisa dikatakan ijma. ${ }^{7}$

\section{Hukum Menabung di Bank}

\footnotetext{
${ }^{7}$ Erwandi Tarmizi, Harta Haram Muamalat Kontemporer, 406
} 
Menabung di bank dengan bunga tertentu tidak diperbolehkan, karena ini termasuk transaksi yang mengandung faktor riba. Allah Swt. telah berfirman:

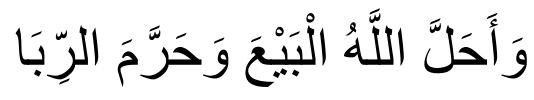

Allah telah menghalalkan perniagaan dan mengharamkan riba (QS. Al-Baqarah [2]: 275).

Bunga yang diambil oleh penabung akan tidak barakah, Allah Swt. berfirman:

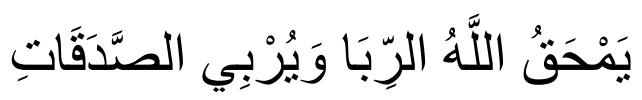

Allah memusnahkan riba dan menyuburkan sedekah (QS. Al-Baqarah [2]: 276).

Riba macam ini termasuk ke dalam riba nasi'ab dan juga riba fadbl (riba perniagaan), sebab nasabah menyetorkan uangnya ke Bank dengan ketentuan uang tabungannya tersebut berada di Bank dalam waktu tertentu dan dengan bunga tertentu pula. ${ }^{8}$

Jika seseorang memang sangat memerlukan membuka rekening di bank konvensional karena gajinya ditransfer oleh perusahaan ke rekening di bank konvensional maka hukumnya diberi keringanan dengan syarat sesegera mungkin menarik uang di rekening, dan jika diberikan bunga oleh bank, maka bunga tersebut merupakan riba yang wajib dibebaskan dari hartanya dengan cara menyalurkannya untuk kepentingan sosial.

Hal ini sesuai dengan lembaga fatwa kerajaan Arab Saudi No. 16501, yang berbunyi "Gaji yang diterima melalui rekening di bank (riba) boleb agar Anda mendapatkan upah hasil kerja dengan syarat jangan tinggalkan di bank setelah masuk rekening agar tidak digunakan oleb bank untuk investasi riba".

\section{Bunga Piutang Diharamkan, Meskipun Sifatnya Fluktuatif}

\footnotetext{
${ }^{8}$ Muhammad Arifin ibn Badri, Riba dan Tinjauan Kritis Perbankan Syari'ah (Bogor: Pustaka Darul Ilmi, 2011), 36.

${ }^{9}$ Tarmizi, Harta Haram Muamalat Kontemporer, 409.
} 
Riba dengan kedua jenisnya: riba nasi'ab dan riba fadbl diharamkan. Hal ini sesuai dengan dalil-dalil dari Al-Qur'an, As-Sunah, dan ijma' ulama, Allah Ta'ala berfiman:

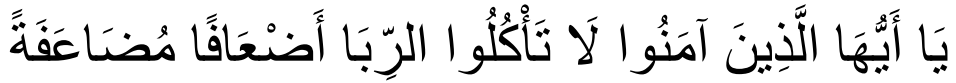

Hai orang-orang yang beriman, janganlah kamu memakan riba dengan berlipat ganda (QS. Ali Imran [3]: 130).

Jabir Ra. meriwayatkan bahwa,

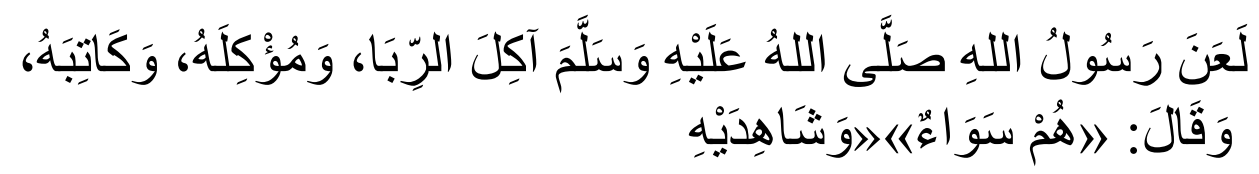

Rasulullah Saw. mengutuk orang yang makan harta riba, yang memberikan riba, penulis transaksi riba, dan dua orang saksi akad riba. Mereka semuanya sama (HR. Muslim). ${ }^{10}$

Dan diriwayatkan dari sahabat Abu Sa'id al-Khudri Ra, bahwa Nabi Muhammad Saw. bersabda:

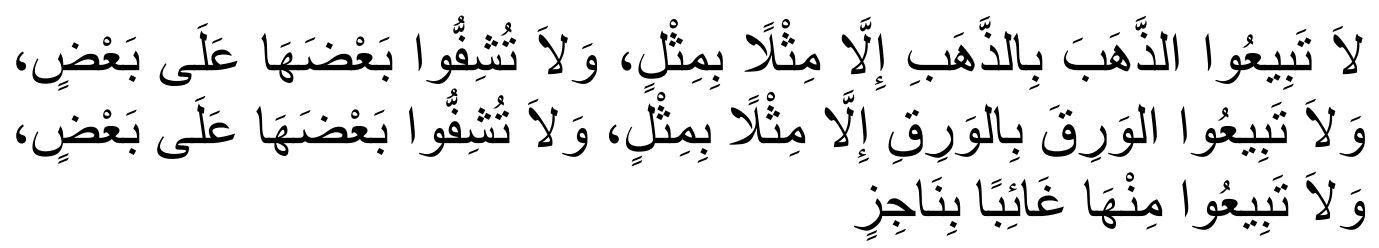

Jangan engkau menjual/membarterkan emas dengan emas, melainkan samasama (beratnya) dan janganlah engkau lebihkan sebagian atas lainnya. Dan janganlah engkau membarterkan perak dengan perak melainkan sama-sama (beratnya), dan janganlah engkau lebihkan sebagian atas lainnya. Dan janganlah engkau menjual sebagian darinya dalam keadaan tidak ada di tempat berlangsungya akad perniagaan dengan emas atau perak yang telah hadir di tempat berlangsungnya akad perniagaan. (HR. Bukhori - Muslim)

${ }^{10}$ Tarmizi, 408. 
Al-'Adalah, Vol. 23, No. 2 (2020)

Dengan dalil-dalil ini dapat diketahui bahwa bunga yang diberikan kepada nasabah dengan prosentase tertentu dari pokok tabungan/modal, baik tiap minggu atau bulan atau tahun, semuanya adalah riba yang diharamkan, dan dilarang dalam syari'at. Hukum ini berlaku baik bunga bersifat fluktuatif atau bersifat tetap dan tidak berubahubah. $^{11}$

\footnotetext{
${ }^{11}$ Badri, Riba dan Tinjauan Kritis Perbankan Syari'ah, 33.
} 


\section{Simpulan}

Setelah dipaparkan di atas, maka dapat dibuat kesimpulan-kesimpulan. Bahwasanya pada dasarnya bank memiliki fungsi menghimpun dana, menyalurkan dana dan memberikan jasa-jasa pelayanan kepada masyarakat. Jasa yang diberikan beragam, hal ini bertujuan untuk mendukung kegiatan perbankan dalam menghimpun dan menyalurkan dana dari dan kepada masyarakat.

Namun demikian, bank konvensional menerapkan bunga dalam transaksinya. Baik dalam tabungan, simpan pinjam, dan lainnya. Jika ditelaah dari kacamata fikih, maka bunga ialah riba. Sebab bunga ialah pinjaman yang dilebihkan. Seluruh lembaga fatwa baik taraf internasional mapun nasional telah sepakat bahwa bunga bank termasuk dalam kategori riba.

Menabung dengan bunga tertentupun tidak diperbolehkan, sebab termasuk dalam kategori riba. Walaupun bunga itu kecil, tetap tidak diperbolehkan. Hal ini sebagimana yang telah dikatakan oleh Allah Swt. dalam QS. Al-Baqarah ([2]: 275-276). Bahwasanya Allah melarang riba dan menghalalkan jual beli.

Walaupun bunga itu bersifat tidak tetap atau fluktuatif, tetap saja tidak boleh karena tetap termasuk dalem kategori riba. Hal ini telah Allah perjelas dalam QS. Ali Imran ([3]: 130). Bahwa Allah melarang untuk melakukan riba dengan berlipat ganda. Dan dalam hadisnya, Nabi Muhammad Saw. mengutuk orang-orang yang melakukan dan berhubungan dengan riba.

Namun, ada keringanan untuk mereka yang gajinya ditransfer ke rekening bank konvensional. Sebagaimana dalam fatwa yang dikeluarkan oleh Lembaga Fatwa Kerajaan Arab Saudi Nomor 16501, "Gaji yang diterima melalui rekening di bank (riba) boleh agar Anda mendapatkan upah hasil kerja dengan syarat jangan tinggalkan di bank setelah masuk rekening agar tidak digunakan oleh bank untuk investasi riba". 


\section{Daftar Pustaka}

Abeng, Tantri. "Pengaruh Aliansi Birokrasi dengan Pengusaha terhadap Etika Bisnis." Demokrasi Politik, Budaya dan Ekonomi Pengalaman Indonesia masa Orde Baru, diedited oleh Elza Peldi Taher. Jakarta: Yayasan Paramadina, 1994.

Badri, Muhammad Arifin ibn. Riba dan Tinjauan Kritis Perbankan Syariah. Bogor: Pustaka Darul Ilmi, 2011.

Dewan Redaksi. Ensiklopedia Islam, Jilid 5. Jakarta: Ichtiar Baru van Hoeve, 2005.

Ismail. Manajemen Perbankan: Dari Teori Menuju Aplikasi. Jakarta: Penerbit Kencana, 2011.

Muslich, Ahmad Wardi. Fiqh Muamalat. Jakarta: Penerbit Amzah, 2017.

Tarmizi, Erwandi. Harta Haram Muamalat Kontemporer. Bogor: PT. Berkat Mulia Insani, 2018. 